\title{
To determine age of appearance of secondary sexual character and age of menarche in working girls of urban slum area
}

\author{
Yadav S. ${ }^{1}$, Bharti R.K. ${ }^{2}$ \\ ${ }^{1}$ Dr. Swati Yadav, Assistant Professor, Department of Pediatrics, Chhattisgarh Institute of Medical Sciences, Bilaspur, \\ Chhattisgarh, India, ${ }^{2}$ Dr. Rajesh Kumar Bharti, Consultant Psychiatrist, Department of Psychiatry, Sadar Hospital, \\ Purnea, Bihar, India.
}

Corresponding Author: Dr. Swati Yadav, Assistant Professor, Department of Pediatrics, Chhattisgarh Institute of Medical Sciences, Bilaspur, Chhattisgarh, India. E-mail: yadavswati93@yahoo.com

\begin{abstract}
Introduction: Adolescence is the developmental phase between childhood and adulthood with specific psychological attributes. In normal girl evidence of sexual maturation characteristically appears not at four or forty, but at 8 or 10 or 12 years of age. At that time, most healthy girls begin to have physical manifestation of the changes in ovarian function that are associated with reproductive maturity. Their breasts start to bud, and hair appears in the pubic and axillary regions. The timely appearance of the menarche gives assurance that the other less recognizable feature of puberty and early adolescence are processing normally or about to be initiated. Method: A cross sectional survey was done by door to door visit in three randomly selected slums of Bilaspur, Chhattisgarh, India. Data was collected on predesigned and pretested pro-forma with the answer to questionnaire regarding various aspects. SMR staging done by taking consent from guardian of minor adolescents and consent from their selves in those who are above 18 years. Result: Out of 696 girls who were examined, it was found that the maximum number $(45.40 \%)$ of adolescents were in $10-13$ years age group and minimum number (27.01\%) were in 17-19 years age group. In 14-16 years 27.58\% girls. In SMR staging of $10-13$ years age group max girls (39.8\%) were in B1 and 55.6\%in P1 and no one in B5 and P5.In 14-16 years age group max (45.8\%) in B4, and only $1.0 \%$ in B1 and max in $\mathrm{P} 3$ and minimum in $\mathrm{P} 1$ that is $38.5 \%$ and $5.2 \%$ respectively. In $17-19$ years, age group max has reached stage B5 with $94.6 \%$ and P5 $72.3 \%$. The Mean age of menarche for all age group was 13.19 years. Conclusion: Nutritional, socioeconomic status, climate, genetic makeup affects age of menarche and pubertal changes knowing the fact that working adolescent from slum will have more nutritional deprived thus can be concluded that poor nutrition and lower socioeconomic status might be responsible for this delay.
\end{abstract}

Keywords: Adolescence, Age of menarche, Sexual character

\section{Introduction}

Adolescence is the developmental phase between childhood and adulthood with specific psychological attributes [1]. WHO (1998)- Adolescence is the period of the life that extends from 10 to 19 years. According to the WHO, term, youth, should be reserved for 15 24year age group and the term, young people, for 10-24 years [2]. NCERT (1999)- Three stages of adolescence(1999) [3]. Early adolescence (9-13 years)Characterized by a spurt of growth and development of secondary sexual characteristics. Mid adolescence (1415 years)- This stage is distinguished by the development of a separate identity from parents, of new

Manuscript received: $14^{\text {th }}$ September 2019

Reviewed: $24^{\text {th }}$ September 2019

Author Corrected: $30^{\text {th }}$ September 2019

Accepted for Publication: $5^{\text {th }}$ October 2019 relationships with peer groups and opposite sex, and experimentation. Late adolescence (16-19 years)- At this stage, adolescents have fully developed physical characteristics (like adults).

Menstruation- It is characteristic bodily function. It is neither a curse nor a sickness. Myth, mystery and superstition have long enveloped the fact about the phenomenon of menstruation. The word menstruation is derived from the Latin word menses, meaning month which as signifies the normal physiological cycle common to all healthy females [4]. In normal girl evidence of sexual maturation characteristically appears not at four or 40 , but at 8 or 10 or 12 years of age. At that time, most healthy girls begin to have physical

Pediatric Review: International Journal of Pediatric Research Available online at: www.medresearch.in 516|P a g e 


\section{Original Research Article}

manifestation of the changes in ovarian function that are associated with reproductive maturity. Their breasts start to bud, and hair appears in the pubic and axillary regions. Within a year, the first episode of menstrual bleeding occurs, providing clear evidence that the ovary is now capable of secreting significant quantities of steroid hormones.

Sometime thereafter, the brain begins to emit cyclic neuroendocrine signals at the intervals of approximately 29 days; these signals cause the pituitary gland to release the hormones responsible for ovulation, and the reproductive capability of a woman is thereby established [5].

The age at menarche is, therefore, a fairly accurate barometer of physical development and the approaching mental and psychosexual maturity of the pubertal girl. The timely appearance of the menarche gives assurance that the other less recognizable feature of puberty and early adolescence are processing normally or about to be initiated [5].

\section{Aims and Objectives}

To determine age of appearance of secondary sexual character and age of menarche. Of working girls of urban Slum of Bilaspur city, Chhattisgarh, India.

\section{Material and Methods}

The present study Sexual maturity staging and menarche of working adolescent female living in slum area done Bilaspur city, Chhattisgarh, India.

Design of study-Cross Sectional study

Place of study: Various Urban Slums of Bilaspur city

Duration of study: September 2010-September 2011

Selection of slum: Total population of Bilaspur city is $3,30,703$.About 167 slums are there in Bilaspur out of that 136 is declared by Government and 31 are undeclared. Total no of population residing in slum is 128318 with population of females 62920.Out of 167 slums, 10 slums were chosen for study purpose by systematic random sampling with the help of table of random number.

\section{Inclusion criteria}

All working adolescent females of Slum Area between 10- 19 years.

\section{Exclusion criteria}

Nonworking adolescent females.

Females having any major systemic illness, major surgery.

\section{Sample Size}

The approach adopted for this community-based study was cross sectional type. By taking prevalence and permissible level of error at $10 \%$ sample size is computed as 696 .

Method of data collection- A cross sectional survey was done by door to door visit. Examination conducted at local Anganbadi centre. Data was collected on predesigned and pretested pro-forma with the answer to questionnaire regarding various aspects like age, sex, religion, address, mother, father, occupation, income, addiction, education and age of menarche. SMR staging done by taking consent from guardian of minor adolescents and consent from their selves in those who are above 18years.

Age- Age of each child was calculated to nearest 6 month (e.g.-10 years 4 month and 11 years 8 month as 12years). Age of most of the children were calculated and cross checked with reference to the events such as some important festival, storm, flood etc. The age was recorded in complete years.

SMR Staging-The sexual growth was assessed for each individual in terms of breast development, presence of axillary and pubic hair. These was graded according to Tanner classification.

Onset of menarche- Each girl of adolescent age was questioned whether they had attended menarche or not and the age of menarche was recorded by recall method.

Analysis of Data- The data collected from the various aspect in present study was analyzed. The results are tabulated and data also subjected to necessary statistical test whenever required. OR statistical analysis Chisquare, Student T test, One way ANOVA was applied.

\section{Result}

In 10-13 years (early adolescent) age group - Breast development $39.8 \%$ girls were in B1 stage, $36.7 \%$ in $\mathrm{B} 2,17.0 \%$ in $\mathrm{B}, 3,5 \%$ in $\mathrm{B}, 4,0.6 \%$ in $\mathrm{B} 5$ stage (Table 1) and in pubic hair development $55.6 \%$ in $\mathrm{P} 1,33.54 \%$ in $\mathrm{P} 2,8.2 \%$ in $\mathrm{P} 3,3.48 \%$ in P4, none in P5 stage (Table 2). In 14-16 years (Mid adolescent) age group-1.04\% in B1, 8.3\% in B2,16.6\% B3, 45.8\% in $\mathrm{B} 4,28.12 \%$ in B5 and in P1 5.2\%, 18.7\% in P2 ,38.54 in P3, 26.04\% in P4 and $11.4 \%$ in P5 stage.

Pediatric Review: International Journal of Pediatric Research Available online at: www.medresearch.in 517|P a g e 


\section{Original Research Article}

Table-1: Different stages of breast development in different age group.

\begin{tabular}{|c|c|c|c|c|c|}
\hline Age in years & B1 & B2 & B3 & B4 & B5 \\
\hline 10 & 50 & 36 & 0 & 0 & 0 \\
\hline 11 & 28 & 20 & 6 & 2 & 0 \\
\hline 12 & 42 & 38 & 12 & 2 & 2 \\
\hline 13 & 6 & 22 & 36 & 20 & 2 \\
\hline 14 & 2 & 12 & 14 & 64 & 8 \\
\hline 15 & 0 & 4 & 16 & 4 & 44 \\
\hline 16 & 0 & 0 & 2 & 4 & 66 \\
\hline 17 & 0 & 0 & 0 & 2 & 50 \\
\hline 18 & 0 & 0 & 0 & 2 & 62 \\
\hline
\end{tabular}

Table-2: Stages of pubic hair appearance in different age group.

\begin{tabular}{|c|c|c|c|c|c|}
\hline Age (years) & P1 & P2 & P3 & P4 & P5 \\
\hline 10 & 60 & 26 & - & - & - \\
\hline 11 & 40 & 14 & 2 & 2 & - \\
\hline 12 & 52 & 24 & 16 & 9 & - \\
\hline 13 & 24 & 42 & 8 & 6 & 2 \\
\hline 14 & 8 & 22 & 26 & 12 & 3 \\
\hline 15 & 2 & 12 & 46 & 34 & 36 \\
\hline 16 & - & 2 & 2 & 14 & 38 \\
\hline 17 & - & - & 2 & 2 & 62 \\
\hline 18 & - & - & - & - & 36 \\
\hline 19 & - & - & & & - \\
\hline
\end{tabular}

In 17-19 years (Late adolescent) age group-No one was found in stage B1, B2, B3 and P1, P2. About 4.25\% in B4, $94.68 \%$ in $\mathrm{B} 5,1.06 \%$ in $\mathrm{P} 3,26.59 \%$ in $\mathrm{P} 4$ and $72.34 \%$ in $\mathrm{P} 5$.

In present study mean age of menarche was between 10-13 years age group was 12.45 years, between 14-16 years age group 13.56 years, $17-19$ years age group 13.56 years with mean age of all 13.19 years.

Table-3: Mean and range of menarcheal age.

\begin{tabular}{|c|c|c|c|c|c|}
\hline $\begin{array}{c}\text { Age } \\
\text { (years) }\end{array}$ & $\begin{array}{c}\text { No. of } \\
\text { females }\end{array}$ & $\begin{array}{c}\text { Girls attained menarche } \\
\text { No. }\end{array}$ & $\mathbf{\%}$ & $\begin{array}{c}\text { Mean age of } \\
\text { menarche }\end{array}$ & $\begin{array}{c}\text { Range of } \\
\text { menarcheal age }\end{array}$ \\
\hline 10 & 86 & - & 0 & - & - \\
\hline 11 & 56 & - & 0 & - & $11-12$ \\
\hline 12 & 94 & 6 & 6.38 & 12 & $12-13$ \\
\hline 13 & 80 & 20 & 25 & 12.9 & $12-13$ \\
\hline 14 & 64 & 36 & 56.25 & 13.5 & $12-15$ \\
\hline 15 & 76 & 68 & 89.47 & 13.6 & $12-14$ \\
\hline 16 & 52 & 48 & 92.30 & 13.6 & $12-15$ \\
\hline 17 & 72 & 72 & 100 & 13.6 & $12-15$ \\
\hline 18 & 52 & 52 & 100 & 13.6 & $12-15$ \\
\hline 19 & 64 & 64 & 100 & 13.5 & \\
\hline
\end{tabular}




\section{Original Research Article}

\section{Discussion}

Secondary sex characteristics from breast development to pubic hair appearance in present study were compared with that of Agrawal D.K et al [6] and various other studies was found to be delayed significantly. In Agrawal D.K.et al study the breast development stages G2-5 were 11.9, 12.8, 13.9, 14.8 years respectively and the mean age of menarche was 12.6 years which is 13.9 years in the present study.

Bhargava SK. et al [7] found that first there was appearance of pubic hair at $9.4 \pm 2.1$ years then development of breast, axillary hair and menarche at $9.7 \pm 2.1$ years, $10.6 \pm 2.1$ years and $11.5 \pm 2.0$ years respectively.

Durge P.M. et al [8] studied in 200 adolescent girls and observed mean age of menarche to be 13.5 years. Kokiwar P.R et al [9] mean age of menarche at 12.8 years. Ghosh et al (10) observed appearance of breast bud between $8-15$ years and mean age to be 12.2 years, pubic hair appearance between 9-16 years and mean 12.4 years.

Lata R Kollur et al [11] found appearance of breast, pubic hair, axillary hair and mean age of menarche to be $10.4 \pm 0.6, \quad 10.6 \pm 0.7, \quad 12.2 \pm 0.7$ and $13.4 \pm 1.34$ years respectively. Rajesh Khadgawat et al [12] did study in school going girls of Delhi found median age of the larche, pubarche and menarche to be 10.8 (10.7-10.9) years, 11.0 years $(10.8-11.2)$ years and 12.4 years $(12.2-$ 12.50 years). F. Tarannum et al [13] found it in their study majority of the study population (69.9\%) had attained menarche between 12-14 years.

The mean age of menarche was $12.52 \% \pm 1.415$. In the study conducted by Dr Dalbir Singh et al, the results showed the age of the females with breast stage 2 to be 9 years $(100 \%), 10$ years $(67 \%)$ or 11 years $(67 \%)$.

Menarche was first seen at 9 years in $7 \%$ cases and was $100 \%$ at 13 years [14]. Age of female with pubic hair stage 2 was 11 years (22\%) and 12 years $(10 \%)$. Pubic hair stage 5 was at 15 years $(67 \%)$ and 16 years $(100 \%)$.

First appearance of axillary hair was at 10 years (8\%) and was $100 \%$ at 16 years.

Limitation of this study is that it should be validated by longitudinal studies in large scale in various slums. The present study should have been done along with hormonal profile of girls as well.

\section{Conclusion}

The age of menarche and sexual maturity staging in present study is comparatively delayed from most of the study may be because most of the studies have been done in either school going or adolescent from well to do families and only few are done in urban slum but they were nonworking girls.

As it is known that nutritional, socioeconomic status, climate, genetic makeup affects age of menarche and pubertal changes knowing the fact that working adolescent from slum will have more nutritional deprived thus can be concluded that poor nutrition and lower socioeconomic status might be responsible for this delay.

\section{What the study adds to the existing knowledge?}

As this adolescents are future adults and going to be future mothers and knowing the fact that there are limited data on working adolescent girls of urban slum regarding their sexual maturity and menarcheal age, the present study will be helpful to assess their sexual development for planning and execution of various programs for better physical and sexual health.

\section{Author's Contribution}

Dr. Swati Yadav: Conceived the idea of study, did data collection supervised the study participated in study design.

Dr. Rajesh Kumar Bharti: Analysis of data and interpretation of results, reviewed related literature, and write up of manuscript.

Funding: Nil, Conflict of interest: None initiated, Permission from IRB: Yes

\section{References}

1. Adolescent in India. A profile, December 2003, United Nations Population Fund.

2. Bhave Swati Y; Bhave's textbook of Adolescent Medicine $1^{\text {st }}$ ed. doi: $10.5005 /$ jp/books/10092.

3. Supriti B, Janeja MK; A profile on adolescent in India. September 2000, UNFPA;3.

4. Rao AR. A study on menstruation in adolescents. J Ind Med Assoc. 1963;40(1).

Pediatric Review: International Journal of Pediatric Research Available online at: www.medresearch.in 519|P a g e 


\section{Original Research Article}

5. Zacharias L. Age of menarche genetic and environmental influences. New Eng J Med. 1969; 280: 868-875. doi: 10.1056/NEJM19690417280 1606.

6. Agrawal D K, Agrawal K N, Upadhyay S K, Mittal R, Prakash R, Rai S. Physical and sexual growth pattern of affluent Indian children from 5 to 18 years of age. Ind J Pediat.1992;29(10):1203-1282.

7. Bhargava SK, Duggal S, Ramanujacharyulu TK, Choudhury P. Pubertal changes and their interrelationship in Indian girls. Ind Pediat. 1980;17(8): 657-665

8. Durge PM and Waradpande U. Impact assessment of health education in adolescent girls. J Obstet Gynecol India. 1993; 43(5):768-772.

9. Kokiwar PR, Saiprasad GS. Anemia among adolescent girls. Indian J Public Health.2007;51(4): 252

10. Ghosh D, Kochhar K, Khanna SD. The study of puberty and after in 557 Indian schoolgirls at Poona. J Obstet Gynaecol India. 1973;23:716-722.

11. Khadgawat R, Marwaha RK, Mehan N, Surana V, Dabas A, Sreenivas V, et al. Age of onset of puberty in apparently healthy schoolgirls from Northern India. Indian Pediat. 2016;53(5):383-387. doi: https://doi. Org / 10. 1007/ s13312-016-0857-5.

13. Tarannum F, Khalique N, Eram U. A communitybased study on age of menarche among adolescent girls in Aligarh. Int J Comm Med Public Health. 2017;5(1): 395-400. doi.org/10.18203-6040.ijcmph20175820.

14. Singh D, Sodhi L: Age estimation of Punjabi adolescent females by noninvasive method viz secondary sex development from Chandigarh zone of northwest India. J Punjab Acad Forensic Medical Toxi. 2012; 12(1):10.

\section{How to cite this article?}

Yadav S, Bharti R.K. To determine age of appearance of secondary sexual character and age of menarche in working girls of urban slum area. Int J Pediatr Res.2019;6(10): 516-520.doi:10.17511/ijpr.2019.i10.04 